\title{
As origens da bioética: do credo bioético de Potter ao imperativo bioético de Fritz Jahr
}

Leo Pessini

\section{Resumo}

Este artigo apresenta as origens históricas da bioética a partir dos trabalhos de Van Rensselaer Potter e de Fritz Jahr, que em dois momentos distintos cunharam a expressão bioética. Traz breve histórico deste último autor e analisa a formulação de cada um deles para o conceito de bioética, considerando seu impacto no contexto das discussões ambientais hodiernas. Conclui apontando a importância de aprofundar a reflexão bioética nos moldes propostos por estes autores, considerando, especialmente, os pontos de intersecção de suas propostas teóricas que podem revelar-se determinantes para a compreensão de um novo paradigma ecológico.

Palavras-chave: Bioética - História. Bioética - Tendências. Temas bioéticos. Filosofia. Europa (Continente). Estados Unidos.

\section{Resumen}

\section{En los orígenes de la bioética: de la creencia bioética de Potter hacia el imperativo bioético de Fritz Jahr}

Este artículo presenta los orígenes históricos de la bioética a partir del trabajo de Van Rensselaer Potter y Fritz Jahr que acuñaron, en dos momentos distintos, la expresión Bioética. Presenta un breve historial de este último autor y analiza la creación del concepto de bioética a cada uno de ellos, teniendo en cuenta su impacto en el contexto de las discusiones ambientales de hoy. Concluye poniendo de relieve el profundizar la reflexión bioética en los modelos propuestos por dichos autores, considerando especialmente los puntos de intersección de sus propuestas teóricas que pueden revelarse determinantes a la comprensión de un nuevo paradigma ecológico.

Palabras-clave: Bioética - Historia. Bioética - Tendencias. Discusiones bioéticas. Filosofia. Europa (Continente). Estados Unidos.

\section{Abstract}

\section{At the origins of bioethics: Potter's bioethical creed to Fritz Jahr's imperative bioethical}

This article presents the historical origins of bioethics from the work of Van Rensselaer Potter and Fritz Jahr who coined into two distinct moments the expression Bioethics. This article displays the brief history of the latter author and analyzes the concept of bioethics formulation for each of them, considering their impact in the context of today's environmental debates. At the end concludes by emphasizing the importance of deepening bioethical reflection as proposed by these authors, especially considering the points of intersection of their theoretical proposals that could prove crucial to the understanding of a new ecological paradigm. Key words: Bioethics- History. Bioethics - Trends. Bioethical issues. Philosophy. Europe. United States.

Doutor pessini@saocamilo-sp.br - Centro Universitário São Camilo, São Paulo/SP, Brasil.

Correspondência

Avenida Pompéia, 888 - Pompéia CEP 05022-000. São Paulo/SP, Brasil.

Declara não haver conflito de interesse. 
O que lhes peço é que pensem a bioética como uma nova ética científica que combina a humildade, responsabilidade e competência numa perspectiva interdisciplinar e intercultural e que potencializa o sentido de humanidade.

Van Rensselaer Potter

Respeite todo ser vivo como princípio e fim em si mesmo e trate-o, se possível, enquanto tal.

Fritz Jahr

A bioética, considerando-se a perspectiva do norte-americano bioquímico Van Rensselaer Potter e a data da publicação de seu primeiro artigo (1970) ${ }^{1}$, completou 43 anos de existência desde que o termo foi cunhado nos Estados Unidos da América (EUA). Pesquisas recentes deslocam esta data para 1927, na Alemanha, e descobrem Fritz Jahr. Fato histórico, nesse sentido, foi o lançamento do livro Fritz Jahr and the foundations of global bioethics: the future of integrative bioethics ${ }^{2}$, divulgado no $8^{\circ}$ Congresso Internacional de Bioética Clínica, realizado em São Paulo (16-19/5/2012). Não sem uma pontinha de ironia, seu folder de divulgação traz a assertiva:

Você sabe quem inventou 'bioética'? Não, não os americanos. Foi Fritz Jahr, um pastor de Halle an der Saale. Em 1927, ele se contrapôs criticamente ao imperativo categórico de Kant com o seu imperativo bioético: 'respeite todos os seres vivos como um fim em si mesmo e trate-os como tal, se possivel' ".

Assim, nossa jornada reflexiva em busca das raízes do neologismo "bioética" se faz em dois momentos fundamentais. Começamos com Potter nos EUA, com seu "credo bioético", e voltamos na história para a década de 20, com Fritz Jahr. Concluímos nossa reflexão com a aproximação entre os dois protagonistas pioneiros na agenda bioética, no urgente resgate do cuidado da Terra, para que tenhamos a garantia do futuro da vida. Este trabalho, portanto, visa ao resgate histórico da contribuição de Van Rensselaer Potter e Fritz Jahr na criação do termo bioética. A bibliografia contempla trabalhos originais dos próprios autores, bem como os referenciais que orientam a construção da discussão ecológica e de sua possível interface com a bioética.

\section{O legado intelectual de Potter}

Potter, que chamou a bioética de "ciência da sobrevivência humana" ${ }^{1}$, traçou para ela uma agenda de trabalho que vai desde a intuição da criação do neologismo até a possibilidade de ser encarada como disciplina sistêmica ou profunda, em 1988. Algumas informações mais importantes desse itinerário são interessantes de recordar, iniciando pela pergunta de como surgiu a palavra bioética.

Nos anos 1970-71 Potter cunha a palavra "bioethics", utilizando-a em dois escritos. Primeiramente, no artigo "Bioethics, science of survival", publicado em Persp Biol Med (1970) ${ }^{3}$; posteriormente, na obra Bioethics: bridge to the future $(1971)^{1}-$ dedicada a Aldo Leopold, renomado professor na Universidade de Wisconsin, que pioneiramente começou a discutir uma "ética da terra". Este neologismo apareceu na mídia em 19 de abril de 1971, quando a revista Time publicou longo artigo com o título "Man into superman: the promise and peril of the new genetic", no qual o livro de Potter foi citado e em cuja contracapa pode-se ler:

Ar e água poluída, explosão populacional, ecologia, conservação - muitas vozes falam, muitas definições são dadas. Quem está certo? As ideias se entrecruzam e existem argumentos conflitivos que confundem as questões e atrasam a ação. Qual é a resposta? O homem realmente está colocando em risco o seu meio ambiente? Não seria necessário aprimorar as condições que ele criou? A ameaça de sobrevivência é real ou se trata de pura propaganda de alguns teóricos histéricos? (...) Esta nova ciência, bioethics, combina o trabalho dos humanistas e cientistas, cujos objetivos são sabedoria e conhecimento. A sabedoria é definida como o conhecimento de como usar o conhecimento para o bem social. A busca de sabedoria tem uma nova orientação porque a sobrevivência do homem está em jogo. Os valores éticos devem ser testados em termos de futuro e não podem ser divorciados dos fatos biológicos. Ações que diminuem as chances de sobrevivência humana são imorais e devem ser julgadas em termos do conhecimento disponível e no monitoramento de "parâmetros de sobrevivência" que são escolhidos pelos cientistas e humanistas ${ }^{4}$.

Potter apresenta a bioética como uma ponte entre a ciência biológica e a ética. Sua intuição con- 
sistiu em pensar que a sobrevivência de grande parte da espécie humana, em uma civilização decente e sustentável, dependia do desenvolvimento e manutenção de um sistema ético. Em 1998, ao olhar retrospectivamente esse primeiro momento de sua reflexão, afirmou:

O que me interessava naquele momento, quando tinha 51 anos, era o questionamento do progresso e para onde a cultura ocidental estava levando todos os avanços materialistas próprios da ciência e da tecnologia. Expressei minhas ideias do que, segundo meu ponto de vista, se transformou na missão da bioética: uma tentativa de responder a pergunta frente à humanidade: que tipo de futuro teremos? E temos alguma opção? Por conseguinte, a bioética transformou-se numa visão que exigia uma disciplina que guiasse a humanidade como uma 'ponte para o futuro (...) ${ }^{5}$.

Na introdução de Bioethics: bridge to the future, afirmava: Se existem duas culturas que parecem incapazes de dialogar - as ciências e humanidades e se isto se mostra como uma razão pela qual o futuro se apresenta duvidoso, então, possivelmente, poderíamos construir uma ponte para o futuro, construindo a bioética como uma ponte entre as duas culturas ${ }^{6}$. As duas margens ligadas por esta ponte são os termos gregos bios (vida) e ethos (ética), sendo que bios representa o conhecimento biológico, a ciência dos sistemas vivos, e ethos o conhecimento dos valores humanos. Potter almejava criar uma disciplina em que promovesse a dinâmica e a interação entre o ser humano e o meio ambiente. Ele persegue a intuição de Aldo Leopold e, sob tal ótica, antecipa-se ao que atualmente se tornou preocupação mundial: a ecologia.

É importante registrar que existe outro pesquisador ao qual se atribui a paternidade do termo bioética. É o obstetra holandês André Hellegers, da Universidade de Georgetown, que seis meses após o lançamento do livro de Potter nomeia com o termo bioética um novo centro de estudos - Joseph and Rose Kennedy Institute for the Study of Human Reproduction and Bioethics - hoje conhecido como Instituto Kennedy de Bioética. Hellegers animou um grupo de discussão de médicos e teólogos (protestantes e católicos) que viam com preocupação crítica o progresso médico tecnológico, o qual apresentava enormes e intrincados desafios aos sistemas éticos do mundo ocidental ${ }^{7}$. Para Reich, historiador da bioética e organizador das duas primeiras edições da Encyclopedia of bioethics $(2003,1995)$ 8,9 , "o legado de Hellegers" está no fato de que entendeu sua missão em relação à bioética como a de alguém que fez a ponte entre a medicina, a filosofia e a éti$c a$ - legado que acabou conquistando hegemonia e tornando-se um campo de estudo revitalizador da ética médica ${ }^{10}$.

Portanto, em seu berço, a bioética tem dupla paternidade e duplo enfoque - de um lado, problemas de macrobioética, com inspiração na perspectiva de Potter, de outro, problemas de microbioética ou bioética clínica, com nítida sustentação no legado de Hellegers. Embora, no presente, a importância das duas perspectivas seja reconhecida pelos estudiosos do campo, Potter não deixou de expressar sua decepção em relação ao curso que a bioética seguiu, mesmo reconhecendo a importância da perspectiva de Georgetown: minha própria visão da bioética exige uma visão muito mais ampla. Com a combinação de conhecimento científico e filosófico (mais tarde chamada Global Bioethics) ${ }^{11}$ pretendia consolidar uma abordagem que fosse além da ética aplicada - como a bioética foi entendida em relação à medicina.

No ano de 1988, Potter amplia a bioética em relação a outras disciplinas, não somente como ponte entre a biologia e a ética, mas com a dimensão de uma ética global: A teoria original da bioética era a intuição da sobrevivência da espécie humana, numa forma decente e sustentável de civilização, exigindo o desenvolvimento e manutenção de um sistema de ética. Tal sistema (a implementação da bioética ponte) é a bioética global, fundamentada em intuições e reflexões alicerçadas no conhecimento empírico proveniente de todas as ciências, porém, em especial, do conhecimento biológico... Na atualidade, este sistema ético proposto segue sendo o núcleo da bioética ponte com sua extensão para a bioética global, o que exigiu o encontro da ética médica com a ética do meio ambiente numa escala mundial para preservar a sobrevivência humana ${ }^{11}$.

Potter, em sua apresentação de vídeo para o IV Congresso Mundial de Bioética (Tóquio, 1998) ${ }^{5}$, lembra que Hans Kung ${ }^{12}$ chamou atenção para uma ética global voltada à política e à economia, em relação a qual todas as nações e povos das mais diferentes tradições culturais e crenças devem se res- 
ponsabilizar. Ressalta que o coração da ética global de Kung está no humano, o que lhe parece louvável, embora considere que essa perspectiva não é suficiente para caracterizar a bioética, pois, para tanto, seria preciso explicitar o respeito pela natureza em diferentes culturas, para além da perspectiva direcionada à cultura judaica e cristã.

Em 1998, Potter expõe a ideia da bioética profunda, retomando o pensamento de Whitehouse, da Universidade de Cleveland. Whitehouse assumiu a ideia dos avanços da biologia evolutiva, em especial o pensamento sistêmico e complexo que comporta os sistemas biológicos. A bioética profunda pretende entender o planeta como grandes sistemas biológicos entrelaçados e interdependentes, em que o centro já não corresponde ao homem, como em épocas anteriores, mas à própria vida; o homem é somente um pequeno elo na grande rede da vida, situando-se na trilha aberta pelo pensamento do filósofo Arne Naess, no início dos anos 70 do século passado ${ }^{13}$.

Ciência e religião e o desafio de garantir o futuro da vida na Terra

Em artigo publicado na revista The Scientist com o sugestivo título "A ciência e a religião devem partilhar da mesma busca em relação à sobrevivência global" ${ }^{14}$, Potter diz que não mais podemos ficar confortáveis com a ideia de que, no futuro, se as coisas piorarem, a ciência terá as respostas. O momento para agir e provar nossa competência ética, bem como técnica, é hoje: Uma questão central para os nossos esforços deve ser a promoção do diálogo entre a ciência e a religião em relação à sobrevivência humana e da biosfera. Durante séculos, a questão dos valores humanos foi considerada como estando para além do campo científico e propriedade exclusiva dos teólogos e filósofos seculares. Hoje devemos sublinhar que os cientistas não somente têm valores transcendentes, mas também os valores que estão embutidos no ethos científico necessitam ser integrados com aqueles da religião e filosofia para facilitar processos políticos benéficos para a saúde global do meio ambiente ${ }^{15}$.

Na busca de companheiros para essa causa, Potter registrou que muitos livros e artigos abordaram os problemas do meio ambiente e saúde humana, mas relativamente poucos autores enfocaram a questão da sobrevivência da espécie humana no futuro. Entre esses, Hans Jonas - The imperative of responsibility: in search of an ethic for the techno- logical age (University of Chicago Press; 1993); Manfred Stanley - The technological conscience: survival and dignity in an age of expertise (University of Chicago Press; 1981) e Hans Kung - mentor e redator da Declaração para uma ética global, documento final do Parlamento Mundial das Religiões (Chicago, 1993) ${ }^{16}$.

É sobre este último autor que Potter vai tecer comentários que interessam à perspectiva de construir uma ponte entre a ciência e a religião. Potter tem uma apreciação crítica em relação à perspectiva da ética global de Kung. Afirma que no cerne da moral religiosa defendida por Kung não está incorporada a preocupação com o rápido crescimento populacional. Destaca que entre as maiores religiões mundiais, em particular o Catolicismo e o Islamismo, estão as que mais contribuem para $a$ atual e assustadora taxa de crescimento populacional.

Ainda segundo Potter, somente a ciência tem as técnicas para analisar mudanças populacionais e seu impacto. Conforme assinalou, ao formular uma ética global Kung apontou que a sobrevivência humana é uma questão-chave, ideia que nenhum outro teólogo até então mencionara. Embora outros líderes religiosos tenham proclamado que a vida é sagrada e defendido os direitos humanos, somente Kung colocou a sobrevivência humana na agenda da reflexão ética. Os cientistas, por sua vez, há muito tempo abraçaram no coração de seus esforços o desafio do bem-estar humano e, implicitamente, a sobrevivência humana, estando credenciados, assim, para colaborar na causa pela sobrevivência humana e da biosfera ${ }^{16}$.

Potter vai além ao dizer que não somente os teólogos, mas também os filósofos seculares, faIharam em pensar sobre a sobrevivência humana e da biosfera como questão ética. Esta reflexão ficou restrita a relações interpessoais ou sociais entre os humanos, excluindo, portanto, questões de comportamento relacionadas ao crescimento populacional e aos problemas ecológicos. Potter destaca como importante na Declaração de Ética Mundial ${ }^{14}$ que não pode haver sobrevivência sem uma ética mundial, que não existirá paz mundial sem a paz entre as religiões. Uma aliança entre crentes e não crentes (ateus, agnósticos e outros), respeitando-se mutuamente, pode também ser necessária para a concretização de uma ética mundial comum a todos os humanos:

Os cientistas devem aplaudir os esforços de Hans Kung ao apontar para a construção de uma aliança reconciliatória entre crentes e aqueles que não são 
fundamentalmente caracterizados como religiosos, incluindo entre estes, penso, a maioria dos cientistas. Precisamos unir as forças frente à responsabilidade global da sobrevivência humana, e seu apelo pelo 'respeito mútuo' é necessário para uma ética mundial comum ${ }^{17}$.

Em vários de seus escritos, Potter manifesta profunda preocupação com o rápido crescimento da população mundial, lembrando que os demógrafos projetam que a mesma dobrará em meados do século XXI. A abordagem desse tema revela seu lado de militante obcecado com a questão populacional, que tem um viés um tanto alarmista. Hoje, a questão demográfica tem uma série de novos fatores cruciais que preocupam, que Potter sequer divisava. Sua pregação de que o crescimento populacional deveria ser interrompido fica ironicamente visível na placa de seu velho carro, na inscrição das letras YES ZPG (Zero Population Growth), que significa "sim, crescimento populacional zero" ${ }^{18}$. No seu credo bioético - que apresentamos na íntegra ao final - explicita que o compromisso em relação à saúde pessoal e familiar se expressa em limitar os poderes reprodutivos de acordo com objetivos nacionais $e$ internacionais. Potter pensa que o problema da superpopulação não poderá ser resolvido enquanto as maiores religiões se opuserem a qualquer tentativa de limitar a fertilidade.

Claro que esse diálogo entre ciência e religião não é fácil e o autor se pergunta como construir consenso e aceitação política pelos governos. A busca por uma ética mundial, partilhada tanto pela religião como pela ciência, não poderia ser expressa em princípios concretos para a ação? Fica a inquietação dessa busca, porém sem a certeza de se encontrar resposta satisfatória neste momento histórico. No diálogo entre ciência e religião, sintetizando as questões-chave, vale destacar o que Potter diz a propósito da Declaração de Ética Mundial:

Estamos conscientes de que as religiões não podem resolver os problemas econômicos, políticos e sociais da Terra. Contudo, elas podem prover o que não podemos conseguir através dos planos econômicos, programas políticos e regulamentações legais. As religiões podem causar mudanças na orientação interior, na mentalidade, nos corações das pessoas e levá-las para uma "conversão" de um "falso caminho" para uma nova orientação de vida (...) As religiões, contudo, são capazes de dar às pessoas um horizonte de sentido para suas vidas e um lar espiritual. Certamente as religiões podem agir com credibilidade somente quando eliminarem os confli- tos que surgem entre elas mesmas e desmantelarem imagens hostis e preconceitos, medos e desconfianças mútuas ${ }^{19}$.

Enfim, ciência e religião travam uma longa e histórica batalha pela hegemonia da verdade ${ }^{20}$. No afã de conquistar tal hegemonia tentam negar uma à outra; agora precisam andar juntas, de mãos dadas, em função de um objetivo maior, uma causa que interessa a toda a humanidade: garantir o futuro da vida (humana e cósmico-ecológica) no planeta Terra. Um dos documentos mais reveladores da personalidade de Potter, que fez da bioética sua causa de vida e conclama os seus seguidores a fazerem o mesmo, se quiserem ser chamados de bioeticistas, expressa-se no credo bioético potteriano ${ }^{21}$. Também as palavras finais de Potter, no vídeo apresentado no IV Congresso Mundial de Bioética, constituem uma agenda de desafio futuro para a bioética. Resgatamos essa declaração, cuja atualidade é indiscutível, ao concluir o tópico sobre sua pessoa, obra e legado para a bioética:

À medida que chego ao ocaso de minha experiência, sinto que a bioética ponte, a bioética profunda e a bioética global alcançaram o umbral de um novo dia que foi muito além daquilo que imaginei. Sem dúvi$d a$, necessitamos recordar a mensagem do ano de 1975 que enfatiza a humildade com responsabilidade como uma bioética básica que logicamente segue da aceitação de que os fatos probabilísticos, ou em parte a sorte, têm consequências nos seres humanos e nos sistemas viventes. A humildade é a consequente característica que assume o 'posso estar equivocado' e exige a responsabilidade de aprender da experiência e do conhecimento disponível. Concluindo, o que lhes peço é que pensem a bioética como uma nova ética científica que combina humildade, responsabilidade e competência, numa perspectiva interdisciplinar e intercultural que potencializa o sentido de humanidade 5 .

\section{Descobrindo a figura e as intuições originais} de Fritz Jahr

Até bem recentemente, o bioquímico norteamericano Van Rensselaer Potter era reconhecido como a primeira pessoa que utilizou o neologismo bioethics. Em 1997, contudo, o professor Rolf Lother, da Universidade Humboldt de Berlim, em conferência em Tübingen, menciona Fritz Jahr, a quem credita ter cunhado a palavra Bio-Ethik em 1927. Segundo seu relato, Lother ouviu pela primeira vez 
o termo "bioética" no início dos anos 90 do século passado. Uma vez que o termo lhe pareceu de alguma forma familiar, começou a procurá-lo nos números publicados do famoso periódico Kosmos, deixado por seu avô, nos quais encontrou o editorial do volume de 1927 e o histórico artigo de Jahr intitulado "Bioética: uma revisão do relacionamento ético dos humanos em relação aos animais e plantas" 22.

A descoberta deste trabalho foi propagada por Eve-Marie Engels, da Universidade de Tübingen, que organizou e editou os anais do congresso que Lother participou. Engels mencionou a descoberta de Lother no artigo "Bioethik", no Metzler Lexicon, em 1999, traduzido para o português e republicado em 2004 na revista brasileira Veritas, de Porto Alegre ${ }^{23}$. Esse texto chamou a atenção do biólogo José Roberto Goldim, que escreveu dois artigos ${ }^{24,25}$ revisitando o início da bioética e a contribuição de Fritz Jahr. Uma análise mais detalhada das ideias de Jahr foi elaborada por Hans-Martin Sass, seu conterrâneo e que trabalhou por longos anos no Instituto Kennedy de Bioética ${ }^{2}$.

Enquanto o pensamento de Fritz Jahr começa a ser investigado, sua vida é ainda um mistério. Uma pesquisa preliminar nos arquivos de sua casa trouxe muitos fatos interessantes. Paul Max Fritz Jahr nasceu em 18 de janeiro de 1895, em Halle, Alemanha Central, onde passou toda a sua vida. Hoje, essa cidade tem aproximadamente 234 mil habitantes. Seus pais, Gustav Maximillian e Auguste Marie Langrock, eram protestantes, mas Fritz foi batizado no ritual católico. Seus estudos iniciais foram feitos na Fundação Francke, ligada ao pietismo protestante de seus idealizadores (August Hermann Francke e Phillipp Jakob Spener). Na universidade, Jahr estudou filosofia, música, história, economia nacional e teologia. Durante o verão de 1915 trabalhou como voluntário de guerra e em 1921 recebeu as sagradas ordens, como pastor.

Jahr começou a ensinar em 1917 e até 1925 trabalhou como professor em 11 diferentes escolas de ensino elementar. A partir de 1925, tornou-se atuante na Igreja. Durante os primeiros quatro anos foi cura da Igreja St. John, em Dieskau (perto de Halle); e entre 1930 e 1933 tornou-se pastor em Kanena. Deve ter sido um tanto sofrido para ele, pois antes de subir ao púlpito para pregar sentia tonturas que o obrigavam a tomar o remédio "bromide".

Em 26 de abril de 1932, Jahr casou-se com Berta Elise Neuholz, mas não tiveram filhos. Viveram na Albert-Schmidt-Strasse 8 , Halle, endereço onde residia desde 1923, quando tinha 18 anos. Nesse local, vive primeiramente com os seus pais e, mais tarde, até 1930, somente com seu pai, que era maníaco-depressivo. Em 1932, tempos turbulentos para a Alemanha, Fritz se aposenta dos serviços da Igreja devido à "exaustão nervosa". Em $1^{\circ}$ de março de 1922, aos 38 anos, se afasta definitivamente do serviço, apenas um mês após Hitler ter assumido o poder no país. Durante a guerra, sua família passa por dificuldades financeiras, agravadas pelo sofrimento de sua esposa, que padecia de esclerose da coluna vertebral. Ela vivia em uma cadeira de rodas e morreu em junho de 1947. Fritz Jahr passou seus últimos anos de vida trabalhando como professor de música. Suas qualidades pedagógicas eram profundamente apreciadas. Morreu em $1^{\circ}$ de outubro de 1953 , aos 58 anos de idade, em sua casa em Halle ${ }^{26}$.

A década de 20 do século passado foi um momento conturbado em termos políticos, econômicos e culturais em toda e Europa e principalmente na Alemanha. A grande depressão começava e os nazistas estavam no processo de assumir a política, a sociedade e a opinião pública. Segundo Sass, naquela época, há 85 anos: Jahr torna claro que o conceito, cultura e missão da bioética estão com a humanidade, talvez, desde os tempos pré-históricos e não foram herança de uma cultura ou de apenas um continente: o respeito ao mundo da vida, aos seres humanos, às plantas, aos animais, ao ambiente natural e social e à terra, a reverência taoísta à natureza, a compaixão budista, com todas as formas de sofrimento da vida, o chamado de Francisco de Assis para a fraternidade com as plantas e os animais, a filosofia de Albert Schwitzer do respeito por todas as formas de vida, são exemplos primordiais da profunda compaixão humana com a vida inanimada e do comprometimento humano em respeitar outras formas de vida ${ }^{27}$.

\section{O nascimento da bioética chamada "integrativa"}

Nos últimos anos começam a surgir publicações a respeito de Fritz Jahr, bem como eventos científicos, dentre os quais se destaca o $1^{\circ}$ Congresso Internacional sobre Fritz Jahr e as raízes europeias da bioética, realizado na cidade de Rijeka (Croácia) no período de 11 a 12 de março de 2011. Nessa mesma cidade portuária do mar Adriático foi realizado, em 2008, o VIII Congresso Mundial de Bioética, organizado pela Associação Internacional de Bioética. Decorreu do congresso sobre Fritz Jahr a Declaração de Rijeka ${ }^{28}$, na qual se afirma: Fritz Jahr já utilizou o termo 'bioética' ("Bio-Ethik") em 1927. Seu 'imperativo bioético' deve orientar a vida pessoal, profissional, cultural, social e política, bem 
como o desenvolvimento e a aplicação da ciência e da tecnologia.

Os signatários da Declaração afirmam que a bioética contemporânea, por vezes, ficou reduzida ao âmbito das questões de ética médica (consentimento informado, princípios, relação médico-paciente, direitos do paciente etc.) e que faz-se preciso a ampliação da bioética com formulação da bioética integrativa: É necessário que a bioética seja substancialmente ampliada e transformada conceitual e metodologicamente, para que possa considerar as diferentes perspectivas culturais, científicas, filosóficas e éticas (abordagem pluralista), integrando estas perspectivas em termos de conhecimentos que orientem e de ações práticas (abordagem integrativa) ${ }^{28}$.

O documento segue afirmando: Esta bioética integrativa terá que harmonizar, respeitar e aprender com a rica pluralidade de perspectivas individuais e coletivas, e com as culturas da comunidade global. Almeja-se que a bioética se torne um campo verdadeiramente aberto de encontro e diálogo de várias ciências e profissões, visões e perspectivas de mundo, que foram reunidas para articular, para discutir e para resolver questões éticas relacionadas à vida como um todo e em cada de suas partes a vida em todos os seus tipos, formas, estágios e manifestações, bem como às condições da vida em geral ${ }^{28}$.

Acreditando no reconhecimento e no crescimento da bioética, considera-se que se tornará uma 'ponte para o futuro', uma 'ciência da sobrevivência', uma sabedoria de como utilizar o conhecimento da medicina e da tecnologia modernas, como Potter definiu em $1970{ }^{28}$.

Fritz Jahr: o imperativo bioético - nas origens da bioética

No citado artigo publicado na Kosmos - "BioEthics: a review of the ethical relationships of humans to animals and plants" - Jahr propôs o imperativo bioético que ampliava para todas as formas de vida o imperativo moral de Kant: age de tal modo que consideres a humanidade, tanto na tua pessoa como na pessoa dos outros, sempre como fim e nunca como simples meio. Essa proposta pode ser traduzida, então, por: Respeite todo ser vivo como princípio e fim em si mesmo e trate-o, se possivel, enquanto tal. $\mathrm{O}$ conceito de bioética de Jahr é mais amplo que o dos pioneiros norte-americanos, incluindo todas as formas de vida.

Jahr, ao refletir sobre o crescente progresso da fisiologia em seu tempo e sobre os desafios morais relacionados com o desenvolvimento de sociedades sempre mais seculares e pluralistas, redefine as obrigações morais em relação a todas as formas de vida, humanas e não humanas, criando um conceito de bioética como disciplina acadêmica, princípio e virtude. Embora não tivesse exercido influência histórica, como era de se esperar, pois viveu em tempos turbulentos tanto política quanto moralmente, sua visão e argumentos éticos são contribuições esclarecedoras para o campo da bioética que ao conciliar ciência e tecnologia exige reflexão (e solução) ético-filosófica, incluindo o entendimento de suas dimensões "geo-éticas" 27.

O pensamento de Jahr em relação ao imperativo bioético está espalhado em diversos de seus escritos, embora não o tenha sistematizado. Por isso, a tentativa de Sass de elaborar a leitura e interpretação coerente do imperativo bioético é extremamente útil. Sass identifica pelo menos seis aspectos que expandem a proposta teórica de Jahr em relação ao imperativo kantiano:

1) O imperativo bioético guia as atitudes éticas e culturais, bem como as responsabilidades nas ciências da vida e em relação a todas as formas de vida (...);

2) O imperativo bioético fundamenta-se na evidência histórica e outras em que a compaixão é um fenômeno empiricamente estabelecido da alma humana (...);

3) O imperativo bioético fortalece e complementa o reconhecimento moral e os deveres em relação aos outros no contexto kantiano e deve ser seguido em respeito à cultura humana e às obrigações morais mútuas entre os humanos (...);

4) O imperativo bioético tem que reconhecer, administrar e cultivar a luta pela vida entre as formas de vida e contextos de vida natural e cultural (...);

5) O imperativo bioético implementa a compaixão, o amor e a solidariedade entre todas as formas de vida como um princípio fundamental e virtude da regra de ouro do imperativo categórico de Kant, que são recíprocos e somente formais;

6) O imperativo bioético inclui obrigações em relação ao próprio corpo e alma como um ser vivo ${ }^{29}$.

É importante registrar que o conceito de bioética não foi pronta e facilmente aceito na Alemanha. Era considerado por demais controverso e rotulado como "produto americano". Somente a partir de 1986 o termo foi oficialmente introduzido e utilizado com mais frequência. E foi justamente Sass, seu compatriota, que resgatou do silêncio da história a figura de Fritz 
Jahr, bem como seu arrojado e avançado conceito de bioética, que alargou os deveres éticos associados aos seres humanos ao incluir os animais e as plantas ao imperativo. A esse respeito cabe considerar que Jahr não inclui os deveres éticos a todos os seres considerando sua utilidade, como é o enfoque atual, mas por reconhecer seu valor intrínseco. Trata-se, portanto, de uma perspectiva horizontal. Potter, ao contrário, segue a tradição de Aldo Leopold, fazendo um recorte longitudinal dos deveres humanos para o futuro, na perspectiva da própria sobrevivência humana ${ }^{30}$.

\section{Considerações finais}

Ao finalizar esta reflexão, poder-se-ia fazer duas perguntas, uma a respeito da origem e outra do futuro: Oh, bioética, de onde vens? Em Fritz Jahr e Potter encontramos indicações de suas origens. Mas, para onde vais? O futuro passa na perspectiva dos dois protagonistas analisados, que se antecipam profeticamente a toda a problemática ecológica de hoje e têm muita sintonia com a causa ecológica das Nações Unidas e de ilustres ativistas na área, entre outros, Mikhail Gorbachev ${ }^{31}$.

Esse último identifica três grandes desafios a serem enfrentados em nosso tempo. O primeiro é a necessidade de manter a paz no mundo. A comunidade internacional tem de também estar unida na luta contra o terrorismo, que não pode ser justificado por nenhuma consideração política ou moral. O segundo, é a luta contra a pobreza. Como pode o "milhão dourado" de pessoas bafejadas pela sorte permanecer indiferente diante do espetáculo da miséria em que se debate a metade da população do planeta, reduzida a viver com um ou dois dólares por dia, passando fome diariamente, sem acesso à água potável e sem condições decentes de higiene? O terceiro desafio identificado está ligado ao meio ambiente. Entramos em sério conflito com o nosso próprio habitat - com a mãe natureza.

Esses três desafios são interdependentes. Sem combater a pobreza, serão também inúteis todas as medidas ecológicas, mas, se não nos preocuparmos com a ecologia, todos os nossos esforços para construir um mundo mais justo estarão fadados ao fracasso e nossos descendentes terão que pagar por nosso comportamento insensato e depredador da natureza. A própria vida na Terra corre o risco de desaparecer, tornando-se somente um episódio efêmero na história do universo ${ }^{32}$.

Os três desafios propostos não dizem respeito somente aos governos e às organizações internacio- nais, mas a cada um de nós. Chegou a hora de todo cidadão do planeta Terra pensar na contribuição pessoal que pode dar para essa tarefa comum: Somos responsáveis, diante das gerações futuras, pela conservação da vida na Terra (...). Hoje, a humanidade precisa de uma nova filosofia de vida, de uma nova ética, que cristalizará os valores fundamentais, comuns a todas as tradições religiosas, uma ética baseada no consenso entre as nações e povos do mundo ${ }^{31}$.

Gorbachev nomeou esse projeto como processo de elaboração de uma ética global e conclui dizendo: a exemplo do grande escritor americano William Faulkner, me recuso a aceitar a possibilidade do fim da humanidade, quaisquer que sejam as provações que tenha que enfrentar. Este é o meu credo de um incorrigível otimista ${ }^{32}$. Lembrando a Carta da Terra, confessa almejar que nosso tempo seja lembrado pelo despertar de uma nova reverência diante da vida, por um compromisso firme de alcançar a sustentabilidade, pela rápida luta pela justiça, pela paz e pela alegre celebração da vida ${ }^{31}$.

Um dos mais importantes documentos bioéticos contemporâneos, elaborado pela Unesco em 2005, intitulado Declaração Universal sobre Bioética e Direitos Humanos ${ }^{33}$, aponta, entre os seus objetivos, promover o respeito da biodiversidade e, entre seus princípios fundamentais, a proteção do meio ambiente, da biosfera e da biodiversidade. Para finalizar, é importante retomar uma reflexão bioética elaborada em seminário convocado pelo governo argentino - realizado em Buenos Aires, em 2004 no intuito de contribuir para a elaboração da citada declaração da Unesco:

Convencidos de que a bioética não se ocupa somente dos problemas éticos originados do desenvolvimento científico e tecnológico, mas também das condições que tornam o meio ambiente humano ecologicamente equilibrado na biodiversidade natural e de todos os problemas éticos relacionados ao cuidado da vida e da saúde, tem como pressuposto básico o conceito de saúde integral entendido na perspectiva biológica, psicológica, social e ambiental, como o desenvolvimento das capacidades humanas essenciais que viabilizem uma vida longeva, saudável e alcançável por todos, o quanto seja possível. (Texto distribuído aos membros da Sociedade Brasileira de Bioética via correspondência em 20/11/2004)

Levando em consideração as perspectivas apresentadas nos últimos congressos mundiais, observa-se que a bioética vai avançando globalmente (geograficamente), ampliando sua compre- 
ensão epistemológica, bem como sua abrangência temática, enfrentando os desafios emergentes e sinalizando prioridades a seguir. Jahr, em 1926-27, e Potter, no início dos anos 70, são os dois pioneiros que apontam para um dos maiores desafios que a humanidade tem nesse início de milênio: a responsabilidade de garantir o futuro da vida na Terra. Ao responder a este desafio, estaremos legando às gerações futuras tanto os resultados de nossas conquistas científicas e tecnológicas quanto um ambiente sustentável e propício à vida em sua plenitude. Como diz T. S. Eliot: Não cessaremos de explorar e no final de toda nossa busca chegaremos onde começamos e conheceremos o lugar pela primeira vez! ${ }^{16}$.

\section{Referências}

1. Potter VR. Bioethics: bridge to the future. Englewood Cliffs: Prentice-Hall; 1971.

2. Muzur A, Sass H-M, editors. Fritz Jahr and the foundations of global bioethics: the future of integrative bioethics. Munster: Lit Verlag; 2012.

3. Potter VR. Bioethics, science of survival. Persp Biol Med. 1970;14:27-153.

4. Potter VR. Op. cit. 1971. p. 7-8.

5. Potter VR. Script do vídeo elaborado e apresentado para o IV Congresso Mundial de Bioética, 4-7 de novembro de 1998, realizado em Tóquio. Mundo Saúde. 1998;22(4):6.

6. Potter VR. Op. cit. 1971. p. 6.

7. Reich WT. The word 'bioethics': its birth and the legacies of those who shaped it. Kennedy Inst Ethics J. 1995;5(1):19-34.

8. Reich WT. Shaping and mirroring the field: the encyclopedia of bioethics. In: Walter JK, Klein EP, editors. The story of bioethics: from seminal works to contemporary explorations. Washington: Georgetown University Press; 2003.

9. Reich WT. Encyclopedia of bioethics. $2^{\text {nd }}$ ed. New York: Macmillan; 1985. Introduction; p. 19-32.

10. Reich WTh. The word 'bioethics': its birth and the legacies of those who shaped it. Kennedy Inst Ethics J. 1994;4:319-35.

11. Potter VR. Global bioethics: building on the Leopold legacy. East Lansing: Michigan State University Press; 1988.

12. Kung $\mathrm{H}$, Schmidt $\mathrm{H}$, editors. A global ethic and a global responsibilities: two declarations. London: SCM Press; 1998.

13. Naess A. The shallow and the deep, long-range ecology movements: a summary. Inquiry. 1973;16:95-100.

14. Potter VR. Science, religion must share quest for global survival. The Scientist. 1994;8(10):1-12.

15. Potter VR. Op. cit. 1994. p. 3.

16. Pessini L, Barchifontaine CP. Problemas atuais de bioética. 10a ed. São Paulo: Loyola; 2012.

17. Potter VR. Op. cit. 1994. p. 7.

18. Whitehouse P. Van Rensselaer Potter: the original bioethicist (in memoriam). Hastings Cent Rep. 2001;31(6):12.

19. Potter VR. Op. cit. 1994. p. 11.

20. Peters T, Nennett G, organizadores. Construindo pontes entre a ciência e a religião. São Paulo: Loyola; 2003.

21. Pessini L. Bioética: das origens à prospecção de alguns desafios contemporâneos. In: Pessini L, Barchifontaine CP, organizadores. Bioética e longevidade humana. São Paulo: Loyola; 2006. p. 5-46.

22. Jahr F. Bio-Ethic: eine umschau über die ethischen. Beziehungen des menschen zu tier und pflanze. Kosmos. Handweiser für Naturfreunde. 1927;24(1):2-4.

23. Engels E-M. O desafio das biotecnias para a ética e a antropologia. Veritas. 2004;50(2):205-28.

24. Goldim JR. Bioética? Origens e complexidade. Rev Hosp Clin Porto Alegre. 2006;26(2):86-92.

25. Goldim JR. Revisiting the beginning of bioethics: the contribution of Fritz Jahr (1927). Perspect Biol Med. 2009;52:377-80.

26. Muzur A, Rincic I. Fritz Jahr (1895-1953): a life story of the 'inventor' of bioethics and a tentative reconstruction of the chronology of the discovery of his word. In: Jahr F. Annual of the Department of Social Sciences and Medical Humanities at University of Rijeka - Faculty of Medicine. 2011;2(4):385-94. 
27. Sass H-M. Post scriptum da II parte: Fritz Jahr, ensaios em bioética e ética 1927-1947. In: Pessini L, Barchifontaine CP, Hossne WS, Anjos MF, organizadores. Ética e bioética clínica no pluralismo e diversidade: teorias, experiências e perspectivas. São Paulo: Centro Universitário São Camilo; 2012. p. 484-94.

28. Declaração de Rijeka sobre o futuro da bioética. Annual of the Department of Social Sciences end Medical Humanities at the University of Rijeka - Faculty of Medicine. [Internet]. 2011[acesso 20 mar. 2013];2(4):587-8. Disponível: http://hrcak.srce.hr/file/110077

29. Sass H-M. European roots of bioethics: Fritz Jahr's 1927 definition and vision of bioethics. In: Covic A, Gosic N, Tomasevic L, editors. From new Medical Ethics to integrative Bioethics. Pargamena: Zabreb; 2009. p. 22.

30. Pessini L, Barchifontaine CP, Hossne WS, Anjos MF, organizadores. Ética e bioética clínica no pluralismo e diversidade: teorias, experiências e perspectivas. São Paulo: Centro Universitário São Camilo; 2012. Parte II, Fritz Jahr: ensaios em bioética e ética 1927-1947. p. 438-82.

31. Gorbachev M. Meu manifesto pela terra. São Paulo: Planeta; 2003.

32. Sass H-M. The earth is a living being: we have to treat her as such! Eubios J Asian Int Bioeth. 2011;21(3):73-7.

33. Organização das Nações Unidas para a Educação, a Ciência e a Cultura. Declaração Universal sobre Bioética e Direitos Humanos. Portugal: Comissão Nacional da Unesco; 2005.

34. Potter VR. Op. cit. p. 193-5. 


\section{Anexo}

\section{O credo bioético de Potter}

1. Creio na necessidade de uma ação terapêutica imediata para melhorar este mundo afligido por grave crise ambiental e religiosa.

Compromisso: trabalharei com os outros para aperfeiçoar a formulação de minhas crenças, desenvolver credos adicionais e procurar um movimento mundial que torne possível a sobrevivência e o aprimoramento do desenvolvimento da espécie humana em harmonia com o meio ambiente natural e com toda a humanidade.

2. Creio que a sobrevivência futura, bem como o desenvolvimento da humanidade, tanto cultural quanto biologicamente, é fortemente condicionado pelas ações do presente e planos que afetam o meio ambiente.

Compromisso: tentarei adaptar um estilo de vida e influenciar o estilo de vida dos outros, bem como ser promotor para um mundo melhor para as futuras gerações da espécie humana, e tentarei evitar ações que coloquem em risco seu futuro, ao ignorar o papel do meio ambiente natural na produção de alimentação e fibras.

3. Creio na unicidade de cada pessoa e em sua necessidade instintiva de contribuir para o aprimoramento de uma unidade maior da sociedade, de forma que seja compatível em longo prazo com as necessidades da sociedade.

Compromisso: ouvirei os pontos de vista dos outros, sejam estes de uma minoria ou de uma maioria, e reconhecerei o papel do compromisso emocional em produzir uma ação efetiva.

4. Creio na inevitabilidade do sofrimento humano que resulta da desordem natural das criaturas biológicas e do mundo físico, mas não aceito passivamente o sofrimento que é resultado da desumanidade do homem para com o próprio homem.
Compromisso: enfrentarei meus próprios problemas com dignidade e coragem. Assistirei os outros na sua aflição e trabalharei com o objetivo de eliminar todo sofrimento desnecessário na humanidade.

5. Creio na finalidade da morte como uma parte necessária da vida. Afirmo minha veneração pela vida, creio na fraternidade humana e que tenho uma obrigação para com as futuras gerações da espécie humana.

Compromisso: viverei de uma forma tal que será benéfica para as vidas de meus companheiros humanos de hoje e do futuro, e que serei lembrado com carinho pelos meus entes queridos.

6. Creio que a sociedade entrará em colapso se o ecossistema for danificado irreparavelmente, a não ser que se controle mundialmente a fertilidade humana, devido ao aumento concomitante na competência de seus membros para compreender e manter a saúde humana.

Compromisso: aperfeiçoarei as habilidades ou um talento profissional que contribuirão para a sobrevivência e aprimoramento da sociedade e manutenção de um ecossistema saudável. Ajudarei os outros no desenvolvimento de seus talentos potenciais, mas ao mesmo tempo cultivando o autocuidado, a autoestima e o valor pessoal.

7. Creio que cada pessoa adulta tem responsabilidade pessoal em relação à sua saúde, bem como responsabilidade para o desenvolvimento desta dimensão da personalidade em sua descendência.

Compromisso: esforçar-me-ei por colocar em prática as obrigações descritas como compromisso bioético para a saúde pessoal e familiar. Limitarei meus poderes reprodutivos de acordo com objetivos, nacionais ou internacionais" 34 . 